\title{
Eye care utilization by older adults in low, middle, and high income countries
}

\author{
Claudia Vela ${ }^{1}$, Elodie Samson ${ }^{1}$, Maria Victoria Zunzunegui ${ }^{2}$, Slim Haddad², Marie-Josée Aubin ${ }^{3}$ and \\ Ellen E Freeman ${ }^{1,3^{*}}$
}

\begin{abstract}
Background: The risk of visual impairment increases dramatically with age and therefore older adults should have their eyes examined at least every 1 to 2 years. Using a world-wide, population-based dataset, we sought to determine the frequency that older people had their eyes examined. We also examined factors associated with having a recent eye exam.

Methods: The World Health Surveys were conducted in 70 countries throughout the world in 2002-2003 using a random, multi-stage, stratified, cluster sampling design. Participants 60 years and older from 52 countries ( $n=$ $35,839)$ were asked "When was the last time you had your eyes examined by a medical professional?". The income status of countries was estimated using gross national income per capita data from 2003 from the World Bank website. Prevalence estimates were adjusted to account for the complex sample design.
\end{abstract}

Results: Overall, only $18 \%(95 \% \mathrm{Cl} 17,19)$ of older adults had an eye exam in the last year. The rate of an eye exam in the last year in low, lower middle, upper middle, and high income countries was 10\%,24\%, 22\%, and 37\% respectively. Factors associated with having an eye exam in the last year included older age, female gender, more education, urban residence, greater wealth, worse self-reported health, having diabetes, and wearing glasses or contact lenses $(p<0.05)$.

Conclusions: Given that older adults often suffer from age-related but treatable conditions, they should be seen on a regular basis to prevent visual impairment and its disabling consequences.

\section{Background}

Older adults have the highest rates of eye disease and visual impairment. Ophthalmic and optometric organizations recommend that older adults visit an eye care professional every 1-2 years to have a comprehensive eye exam [1,2]. Those with diabetes should visit an eye care professional every year $[1,2]$. Several studies have examined compliance with these recommendations in highincome countries like the United States, Australia, and Canada [3-6]. For example, in the United States, 65-69\% of adults aged 50 years and older visited an eye care provider in the last year [4]. In Australia, 62\% of older Australians visited an eye care professional in the last 2 years [5]. However, very few studies examining this issue have been done in low and middle income countries with

\footnotetext{
* Correspondence: ellen.e.freeman@umontreal.ca

'Hôpital Maisonneuve-Rosemont Recherche ophtalmologie, F131 5415

boulevard de l'Assomption, Montreal, QC H1T 2M4, Canada Full list of author information is available at the end of the article
}

the exception of China, India, and Iran [7-9]. In rural India, $64 \%$ of adults ages 40 years and older had never had an eye exam. We sought to determine the prevalence of an eye exam in the last year and its associated factors in 52 high, middle, and low income countries throughout the world using data from the World Health Survey (WHS).

\section{Methods \\ World health survey \\ Study Population}

The WHS was coordinated by the World Health Organization (WHO) to collect population-based, nationally representative, high quality cross-sectional data from 70 countries within 6 world regions [10]. This paper focuses on the 52 countries that asked about eye care utilization including 18 African countries, 13 European countries, 7 countries from Central and South America, 4 Middle Eastern countries, 5 from Southeast Asia, and
C Biomed Central 
5 from the Western Pacific in 2002-2003. Survey institutions were selected by WHO in each country and these institutions carried out the survey according to WHS procedures. Informed consent was obtained from all participants and ethics approval was obtained from every institution that was involved in the study.

\section{Sampling Strategy}

A multi-stage stratified random cluster sampling strategy was used to identify the participants to be contacted in each country. All sampling plans were reviewed by WHO before implementation. Strata were created based on 3 factors: region, socioeconomic status, and presence of a healthcare facility. Lists of households were obtained from population registries, voter lists, manual enumeration, or other methods. Households within the sampling units were randomly selected from these lists. Each member of the household was listed by the household informant. Within each household, an adult 18 years or older was randomly selected using a Kish table to complete the survey. Non-response was carefully documented. Response rates were very good with an average household response rate of $87 \%$ and an average individual response rate of $97 \%$.

\section{Survey}

All surveys were interviewer-administered in person in local languages. Questionnaires were translated into 68 local languages using standard techniques. Briefly, forward translation was done locally by a bilingual multidisciplinary group. Back-translation was then done by an independent group. A review of the back-translation was also done at WHO. Any discrepancies were resolved. A review of the translated instrument was then done by a panel of experts. Detailed background information was obtained on the age, gender, urban versus rural dwelling, and education of the participant. Participants were asked to rate their general health status and whether they wore eyeglasses or contact lenses. Participants who were aged 60 years and older were asked "When was the last time you had your eyes examined by a medical professional?".

The wealth of the participant was estimated by measuring asset ownership using the widely used method of Filmer and Pritchett [11]. This asset index had good internal coherence and robustness to the selection of variables used [11]. This measure is considered to represent the household's long-run economic status rather than its current economic status. WHS participants were asked about their ownership of various items (i.e. bicycle, television, computer).

\section{Income Status of Country}

We also obtained data on the income status of the 52 countries from the World Bank website using data from 2003 [12]. According to the website, gross national income was converted to U.S. dollars using the Atlas method and was divided by the mid-year population. The Atlas method of conversion is used by the World Bank to smooth fluctuations in prices and exchange rates. We categorized this variable into 4 categories using World Bank classifications. The 4 categories were low $(<\$ 66)$, lower middle (\$766-\$3035), upper middle (\$3036-\$9385), and high income (> \$9385) [12].

\section{Data analysis}

There were 46,209 people who reported their age to be 60 years or older. We limited our analyses to the 35,839 respondents from the 52 countries who answered the question on the time of their last eye exam who reported their age to be 60 years or older (78\% of the total). Means, standard deviations, and percentages were estimated. Prevalence rates were adjusted for the complex survey design although 3 countries (Slovenia, Guatamala, Zambia) did not report survey design information and therefore unweighted estimates are given for these 3 countries. Logistic regression analyses were performed to identify factors associated with having an eye exam in the last year. A random effects model with an exchangeable correlation structure was used to account for the multilevel nature of the data (people within countries). Principal components analysis was used to determine the weights for the index of the asset variables according to the method of Filmer and Pritchett [11]. The index was divided into tertiles for use in the regression model. Stata Version 11 was used for the analyses (StataCorp, College Station Texas, USA) while the map was created in SAS Version 9.2 (Cary, North Carolina, USA).

\section{Results}

The study population is described in Table 1. Respondents come from 52 countries with the average sample size of participants aged 60 years and older being 692 people per country with a range of 46 (United Arab Emirates) to 6298 (Mexico) people. The majority of the participants come from low or lower middle income countries (65\%). Correspondingly, $49 \%$ of the participants had less than a primary school education.

Overall, only $18 \%(95 \%$ CI 17,19$)$ had an eye exam in the last year (Table 2). The percentage of people having an eye exam in the last year in low, lower middle, upper middle, and high income countries was $10 \%, 24 \%, 22 \%$, and $37 \%$ respectively (see list of countries in footnote to Table 2). A map showing the percentages by country can be found in Figure 1. The countries in the darkest colors have the lowest rates of an eye exam in the last year with countries in Africa and Southeast Asia having the lowest rates. Strikingly, 38\% of people overall reported never having an eye exam (Table 2). The rate of never having an eye exam in low, lower middle, upper middle, and high income countries was $61 \%, 20 \%, 26 \%$, and $5 \%$ 
Table 1 Descriptive statistics of WHS study population who are 60 years and older

\begin{tabular}{ll}
\hline Variable & $\begin{array}{l}\text { Overall } \\
\text { Mean (SD) or } \% \\
\mathbf{N}=\mathbf{3 5 , 8 3 9}\end{array}$ \\
\hline $\begin{array}{ll}\text { Income status of country of origin } \\
\text { Low }\end{array}$ \\
$\quad 31 \%$ \\
Lower middle & $34 \%$ \\
Upper middle & $28 \%$ \\
High & $7 \%$ \\
\hline Age, Years & $70(8)$ \\
\hline Female gender & $56 \%$ \\
\hline Highest education level & \\
No formal schooling & $33 \%$ \\
Less than primary school & $16 \%$ \\
Completed primary school & $20 \%$ \\
Completed secondary school & $19 \%$ \\
Completed high school & $7 \%$ \\
Completed college/university & $5 \%$ \\
Completed post-graduate degree & $1 \%$ \\
\hline Setting & \\
Urban or Semi-Urban & $51 \%$ \\
Rural & $49 \%$ \\
\hline Health status & \\
Very good & $8 \%$ \\
Good & $28 \%$ \\
\hline Bair & $42 \%$ \\
\hline Diabetes or very bad &
\end{tabular}

respectively. Of those reporting a diagnosis of diabetes (9\%), 32\% reported an eye exam in the last year while $19 \%$ had never had an exam.

We examined demographic, health, and ocular factors associated with having an eye exam in the last year (Table 3). Older people, women, those with more education, those with greater wealth, those with worse reported health, those with diabetes, and those who wore glasses or contact lenses were more likely to report having an eye exam in the last year $(\mathrm{P}<0.01)$. Those who lived in a rural area were less likely to report having an eye exam in the last year compared to those living in an urban or semi-urban area $(\mathrm{P}<0.01)$. There was no evidence that the factors differed by the income status of the country as odds ratios were very similar between income strata (data not shown).

\section{Discussion}

Older adults have the highest rates of visual impairment due to age-related eye diseases and conditions like cataract, glaucoma, presbyopia, and age-related macular degeneration $[13,14]$. Also, older patients with diabetes are at risk of developing diabetic retinopathy [15]. Therefore, older adults, more than any other age group, need to have routine eye examinations at least every $1-2$ years. Most older people who already know that they have a chronic eye disease need to be seen at least every year, if not more frequently.

To our knowledge, this is the first study to examine eye care utilization on a world-wide basis. Very few

Table 2 Ocular or eye exam characteristics by income status of the country of the participant

\begin{tabular}{|c|c|c|c|c|c|}
\hline Variable & $\begin{array}{l}\text { Overall } \\
\% * \\
N=35,839\end{array}$ & $\begin{array}{l}\text { LIC } \\
\% * \\
N=11,020\end{array}$ & $\begin{array}{l}\text { LMIC } \\
\% * \\
N=12,157\end{array}$ & $\begin{array}{l}\text { UMIC } \\
\%{ }^{*} \\
N=10,057\end{array}$ & $\begin{array}{l}\text { HIC } \\
\% * \\
N=2,605\end{array}$ \\
\hline Wears glasses or contacts & $47 \%$ & $27 \%$ & $62 \%$ & $64 \%$ & $83 \%$ \\
\hline \multicolumn{6}{|l|}{ When was your last eye exam } \\
\hline Within last 12 months & $18 \%$ & $10 \%$ & $24 \%$ & $22 \%$ & $37 \%$ \\
\hline $1-2$ years ago & $16 \%$ & $9 \%$ & $21 \%$ & $20 \%$ & $27 \%$ \\
\hline 3-4 years ago & $9 \%$ & $5 \%$ & $11 \%$ & $12 \%$ & $13 \%$ \\
\hline 5 years ago & $3 \%$ & $3 \%$ & $4 \%$ & $3 \%$ & $3 \%$ \\
\hline More than 5 years ago & $16 \%$ & $12 \%$ & $20 \%$ & $17 \%$ & $15 \%$ \\
\hline Never & $38 \%$ & $61 \%$ & $20 \%$ & $26 \%$ & $5 \%$ \\
\hline \multicolumn{6}{|l|}{ Diabetics } \\
\hline Eye exam in last 12 months & $32 \%$ & $18 \%$ & $37 \%$ & $36 \%$ & $43 \%$ \\
\hline Never had an eye exam & $19 \%$ & $38 \%$ & $11 \%$ & $14 \%$ & $2 \%$ \\
\hline
\end{tabular}

LIC = low income countries (Bangladesh, Burkina Faso, Chad, Comoros, Congo, Cote d'Ivoire, Ethiopia, Ghana, India, Kenya, Lao, Malawi, Mali, Mauritania, Myanmar, Nepal, Pakistan, Senegal, Vietnam, Zambia, Zimbabwe)

LMIC = lower middle income countries (Bosnia Herzegovina, Brazil, China, Dominican Republic, Ecuador, Georgia, Guatemala, Kazakhstan, Morocco, Namibia,

Paraguay, Philippines, Russian Federation, South Africa, Sri Lanka, Swaziland, Tunisia, Ukraine)

UMIC = upper middle income countries (Croatia, Czech Republic, Estonia, Hungary, Latvia, Malaysia, Mauritius, Mexico, Slovakia, Uruguay)

$\mathrm{HIC}=$ high income countries (Slovenia, Spain, United Arab Emirates)

*Data are weighted to account for the survey design except for 3 countries (Guatemala, Zambia, and Slovenia) which did not include survey design data 


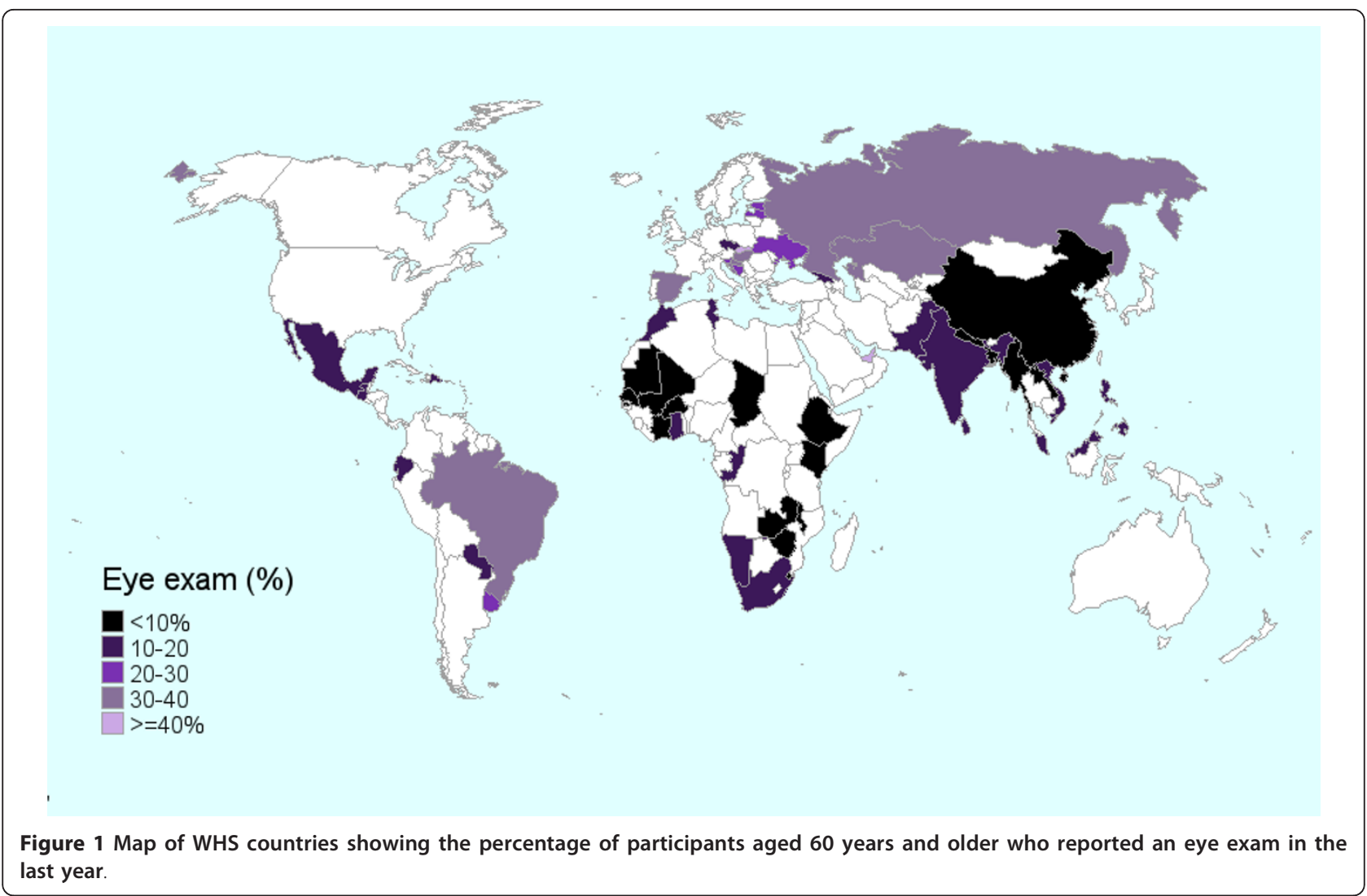

studies have examined the rate of eye care utilization in low or middle income countries [7-9]. We found very low rates of eye care utilization in the world with an overall rate of only $18 \%$ of older adults having seen an eye care professional in the last year. The rate varied 4fold depending on the income status of the country.

Prior research on eye care utilization has typically focused on high income countries like the United States, Australia, and Canada [3-6,16-18]. Three studies from these high-income countries reported that $60-70 \%$ of older adults visited an eye care provider in the last year [3-5]. In the WHS data, only 3 of the 20 high-income countries asked the question on eye exams (Slovenia, Spain, and the United Arab Emirates (UAE)). The rates of an eye exam in the last year in those aged 60 years and older from these three countries were $27 \%$ (unweighted), $37 \%$, and $47 \%$ respectively. These rates are much lower than the rates seen in the United States, Australia, and Canada.

In low or middle income countries, we only found three studies that reported on this topic. In a populationbased study in Tehran, Iran, an upper middle income country, $13 \%$ of adults aged 60 years and older had never seen an eye care professional [7]. Iran did not participate in the WHS so we are unable to compare our results. In a study of people with diabetes in China, a lower middle income country, $43 \%$ of urban people and $69 \%$ of rural people had never had an eye exam [9]. There were not enough people who reported having diabetes living in rural China in the WHS to examine this. However, $46 \%$ of urban and $85 \%$ of rural Chinese WHS participants reported never having an eye exam. In a study done in rural India, a low income country, $64 \%$ of people aged 40 years and older had never had an eye exam [8]. In the WHS data from rural India, we found that $55 \%$ of adults aged 60 and older reported never having an eye exam. Because the same age ranges were not included, it is difficult to directly compare the results.

Certain factors were independently related to eye care utilization regardless of the income status of the country. Men had lower rates of eye exams than women. This finding is consistent with other literature $[5,6,17,19]$. Also, those with lower education had lower rates of eye exams. This finding is also consistent with other literature $[16,19,20]$. If people do not understand that vision loss is not a normal part of aging and that services may exist to correct this vision loss, they are not likely to have an eye exam. It is also possible that education is confounded with other factors that affect eye exam utilization such as income, culture, or empowerment. Independent from education, those in rural areas were less likely to have an eye exam in the last year than those in urban areas. This may 
Table 3 Factors independently associated with having an eye exam in the last year from random effect multiple logistic regression model

\begin{tabular}{lll}
\hline $\mathbf{n}=\mathbf{3 1}, \mathbf{5 3 0}$ & OR & $\mathbf{9 5 \%} \mathbf{C l}$ \\
\hline Age & 1.01 & $1.00,1.01$ \\
\hline Female gender & 1.17 & $1.10,1.25$ \\
\hline Highest education level & & \\
$\quad$ No formal schooling & 1.00 & \\
$\quad$ Less than primary school & 1.27 & $1.12,1.43$ \\
$\quad$ Completed primary school & 1.29 & $1.14,1.45$ \\
$\quad$ Completed secondary school & 1.50 & $1.31,1.71$ \\
$\quad$ Completed high school & 1.99 & $1.70,2.33$ \\
$\quad$ Completed college/university & 2.00 & $1.68,2.38$ \\
$\quad$ Completed post-graduate degree & 2.84 & $2.11,3.82$ \\
\hline Wealth index of participant & & \\
$\quad$ Lowest category & 1.00 & \\
$\quad$ Middle category & 1.28 & $1.19,1.38$ \\
$\quad$ Upper category & 1.62 & $1.46,1.80$ \\
\hline Setting & & \\
$\quad$ Urban & 1.00 & \\
$\quad$ Rural & 0.75 & 0.70 .0 .81 \\
\hline Health status & & \\
$\quad$ Very good & 1.00 & \\
$\quad$ Good & 1.17 & $1.01,1.35$ \\
$\quad$ Fair & 1.38 & $1.20,1.59$ \\
Bad or very bad & 1.58 & $1.36,1.84$ \\
\hline Diabetes & 1.67 & $1.53,1.83$ \\
\hline Wears glasses or contact lenses & 2.26 & $2.10,2.45$ \\
\hline
\end{tabular}

be due to the difficulty in finding an eye care provider in rural areas. Other studies have also documented a lower rate of eye care utilization in rural versus urban areas $[9,21]$. Those who were in worse self-reported health were more likely to have had an eye exam, which suggests that contact with a healthcare provider may have spurred an eye exam. Those who had diabetes were more likely to have had an eye exam in the last year although only $32 \%$ had had an eye care exam in the last year. Current recommendations are that diabetics should see an eye care professional every year. Those who wore glasses or contact lenses were more likely to see an eye care professional in the last year, which is important since refractive status can change and needs to be evaluated on a regular basis.

Those with higher income in the WHS were more likely to have an eye exam in the last year. Few prior studies have examined income. Those that did report inconsistent findings on this relationship. In China, monthly income was not associated with use of eye care services in diabetic patients [9]. In high income countries like the United States, women with a higher income were more likely to have had an eye exam in the last 2 years [20]. Also in the U.S., using data from the National Health Interview Survey, the probability of having a dilated eye exam in those with an eye disease increased with higher income status [17].

Our findings on eye care utilization are consistent with other literature showing that gender, education, and rural residence are related to health services utilization. Men are reported to use less health care services than women including general practice utilization, hypertension and diabetes treatment [22-25] although men may be more likely to be hospitalized $[26,27]$. People with less education are less likely to use preventive health services (mammogram, Pap test, dentist) [28,29], maternal health care [30], and reproductive services [31]. One study found that health literacy significantly mediated educational disparities in the receipt of the influenza vaccine in older adults [32]. People living in rural areas in a variety of countries are reported to use less healthcare services including antenatal care [33,34], dental services [35,36], physician visits [37], and immunizations [38] compared to people living in urban or suburban areas.

The WHS is a rich, under-utilized source of population-based data from around the world. We augmented the WHS data with data from the World Bank on the income status of the country. Most of the countries had very good response rates which allows us to calculate prevalence estimates that are representative of the entire country. Limitations of the WHS data include that we do not have comprehensive data on barriers to eye care utilization or presence of an eye disease via an eye exam. Eye care utilization is based on self-report which could lead to misclassification if participants do not have a good memory of their last eye exam. We do not know whether the participant visited an ophthalmologist/optometrist/or other medical professional. Only $78 \%$ of those aged 60 years and older answered the question on eye care utilization although $75 \%$ of this missing data came from upper middle or high income countries which simply did not administer this question. The rate of missing data for this question in low and lower middle income countries was $10 \%$ and $10 \%$ respectively. The study design is cross-sectional which prohibits us from examining trends in eye care utilization over time and from examining the temporality of the exposures and the outcome.

\section{Conclusions}

These global data indicate that eye care utilization in older adults in much of the world is terribly low. Consequences of vision loss in older adults go beyond the inability to see since vision loss is a determinant of disability and dependency in old age [39,40]. Given that older adults often suffer from age-related but treatable conditions such as cataract, presbyopia, glaucoma, and 
age-related macular degeneration, they should be seen on a regular basis to minimize the risk of visual impairment and blindness.

\section{Acknowledgements}

This work was funded by a grant from the Canadian Institutes of Health Research (MOP 106533). Dr. Freeman is supported by a salary award from the Fonds de Recherche en Santé du Québec. The funding bodies had no role in the design, analysis, or write-up of the project. This article uses data from the WHO World Health Survey.

\section{Author details}

${ }^{1}$ Hôpital Maisonneuve-Rosemont Recherche ophtalmologie, F131 5415 boulevard de I'Assomption, Montreal, QC H1T 2M4, Canada. ${ }^{2}$ Centre de Recherche de Centre Hospitalier de I'Université de Montréal, Montreal, Quebec, Canada. ${ }^{3}$ Department of Ophthalmology, Université de Montréal, Montreal, Quebec, Canada.

\section{Authors' contributions}

CV helped with data analysis and the literature review. ES constructed the World Health Survey world-wide dataset and cleaned the data. EF supervised CV and ES and performed some of the data analysis. All authors (CV, ES, MVZ, SH, MJA, and EF) provided input on the interpretation of the results and the manuscript and gave final approval of the manuscript.

\section{Competing interests}

The authors declare that they have no competing interests.

Received: 12 September 2011 Accepted: 3 April 2012

Published: 3 April 2012

\section{References}

1. Preferred Practice Patterns. [http://one.aao.org/CE/PracticeGuidelines/ PPP_Content.aspx?cid = 64e9df91-dd10-4317-8142-6a87eee7f517]

2. Adult Vision: Over 60 Years of Age. [http://www.aoa.org/x9454.xml]

3. Jin YP, Trope GE: Eye care utilization in Canada: disparity in the publicly funded health care system. Can J Ophthalmol 2011, 46(2):133-138.

4. McGwin G, Khoury R, Cross J, Owsley C: Vision impairment and eye care utilization among Americans 50 and older. Curr Eye Res 2010, 35(6):451-458

5. Wang JJ, Mitchell P, Smith W: Use of eye care services by older Australians: the Blue Mountains Eye Study. Aust N Z J Ophthalmol 1999, 27(5):294-300

6. Puent BD, Klein BE, Klein R, Cruickshanks KJ, Nondahl DM: Factors related to vision care in an older adult cohort. Optom Vis Sci 2005, 82(7):612-616.

7. Fotouhi A, Hashemi H, Mohammad K: Eye care utilization patterns in Tehran population: a population based cross-sectional study. BMC Ophthalmol 2006, 6:4.

8. Robin AL, Nirmalan PK, Krishnadas R, Ramakrishnan R, Katz J, Tielsch J, Thulasiraj RD, Friedman DS: The utilization of eye care services by persons with glaucoma in rural south India. Trans Am Ophthalmol Soc 2004, 102:47-54, discussion 54-45.

9. Wang D, Ding X, He M, Yan L, Kuang J, Geng Q, Congdon N: Use of eye care services among diabetic patients in urban and rural China. Ophthalmology 2010, 117(9):1755-1762.

10. World Health Survey. [http://www.who.int/healthinfo/survey/en/index. html].

11. Filmer D, Pritchett LH: Estimating wealth effects without expenditure data-or tears: an application to educational enrollments in states of India. Demography 2001, 38(1):115-132.

12. GNI per capita, Atlas Method. [http://data.worldbank.org/indicator/NY.GNP. PCAP.CD].

13. Resnikoff S, Pascolini D, Etya'ale D, Pararajasegaram R, Kocur I, Pokharel GP, Mariotti SP: Global data on visual impairment in the year 2002. Bull World Health Organ 2004, 82(11):844-851.

14. Resnikoff S, Pascolini D, Mariotti SP, Pokharel GP: Global magnitude of visual impairment caused by uncorrected refractive errors in 2004. Bull World Health Organ 2008, 86(1):63-70.
15. Klein R, Lee KE, Gangnon RE, Klein BE: The 25-year incidence of visual impairment in type 1 diabetes mellitus the wisconsin epidemiologic study of diabetic retinopathy. Ophthalmology 2010, 117(1):63-70.

16. Orr P, Barron $Y$, Schein OD, Rubin GS, West SK: Eye care utilization by older Americans: the SEE Project. Salisbury Eye Evaluation. Ophthalmology 1999, 106(5):904-909.

17. Zhang X, Saaddine JB, Lee PP, Grabowski DC, Kanjilal S, Duenas MR, Narayan KM: Eye care in the United States: do we deliver to high-risk people who can benefit most from it? Arch Ophthalmol 2007, 125(3):411-418.

18. Lee DJ, Lam BL, Arora S, Arheart KL, McCollister KE, Zheng DD, Christ SL, Davila EP: Reported eye care utilization and health insurance status among US adults. Arch Ophthalmol 2009, 127(3):303-310.

19. Haymes SA, Leston JD, Ferucci ED, Etzel RA, Lanier AP: Visual impairment and eye care among Alaska Native people. Ophthalmic Epidemiol 2009, 16(3):163-174

20. Schaumberg DA, Christen WG, Glynn RJ, Buring JE: Demographic predictors of eye care utilization among women. Med Care 2000, 38(6):638-646.

21. Keeffe JE, Weih LM, McCarty CA, Taylor HR: Utilisation of eye care services by urban and rural Australians. Br J Ophthalmol 2002, 86(1):24-27.

22. Gu Q, Burt VL, Paulose-Ram R, Dillon CF: Gender differences in hypertension treatment, drug utilization patterns, and blood pressure control among US adults with hypertension: data from the National Health and Nutrition Examination Survey 1999-2004. Am J Hypertens 2008, 21(7):789-798.

23. Santosh J, Crampton P: Gender differences in general practice utilisation in New Zealand. J Prim Health Care 2009, 1(4):261-269.

24. Travassos C, Viacava F, Pinheiro R, Brito A: Utilization of health care services in Brazil: gender, family characteristics, and social status. Rev Panam Salud Publica 2002, 11(5-6):365-373.

25. Shalev V, Chodick G, Heymann AD, Kokia E: Gender differences in healthcare utilization and medical indicators among patients with diabetes. Public Health 2005, 119(1):45-49.

26. Suominen-Taipale AL, Martelin T, Koskinen S, Holmen J, Johnsen R: Gender differences in health care use among the elderly population in areas of Norway and Finland. A cross-sectional analysis based on the HUNT study and the FINRISK Senior Survey. BMC Health Serv Res 2006, 6:110.

27. Song J, Chang RW, Manheim LM, Dunlop DD: Gender differences across race/ethnicity in use of health care among Medicare-aged Americans. Womens Health (Larchmt) 2006, 15(10):1205-1213.

28. Sambamoorthi U, McAlpine DD: Racial, ethnic, socioeconomic, and access disparities in the use of preventive services among women. Prev Med 2003, 37(5):475-484

29. Noyce M, Szabo A, Pajewski NM, Jackson S, Bradley TG, Okunseri C: Primary language spoken at home and children's dental service utilization in the United States. J Public Health Dent 2009, 69(4):276-283.

30. McTavish S, Moore S, Harper S, Lynch J: National female literacy, individual socio-economic status, and maternal health care use in subSaharan Africa. Soc Sci Med 2010, 71(11):1958-1963.

31. Potter J, Trussell J, Moreau C: Trends and determinants of reproductive health service use among young women in the USA. Hum Reprod 2009, 24(12):3010-3018.

32. Bennett IM, Chen J, Soroui JS, White S: The contribution of health literacy to disparities in self-rated health status and preventive health behaviors in older adults. Ann Fam Med 2009, 7(3):204-211.

33. Tran TK, Nguyen CT, Nguyen HD, Eriksson B, Bondjers G, Gottvall $K$, Ascher $\mathrm{H}$, Petzold M: Urban - rural disparities in antenatal care utilization: a study of two cohorts of pregnant women in Vietnam. BMC Health Serv Res 2011, 11(1):120.

34. Wu Z, Lei P, Hemminki E, Xu L, Tang S, Li X, Raven J, Gao J, Tolhurst R: Changes and Equity in Use of Maternal Health Care in China: from 1991 to 2003. Matern Child Health J 2011, 16(2):501-509.

35. Vargas CM, Yellowitz JA, Hayes $\mathrm{KL}$ : Oral health status of older rural adults in the United States. J Am Dent Assoc 2003, 134(4):479-486.

36. Martin $A B$, Vyavaharkar $M$, Veschusio $C$, Kirby $H$ : Rural-urban Differences in Dental Service Utilization Among an Early Childhood Population Enrolled in South Carolina Medicaid. Matern Child Health J 2010, 16(1):203-211.

37. Salinas JJ, Al Snih S, Markides K, Ray LA, Angel RJ: The rural-urban divide: health services utilization among older Mexicans in Mexico. $J$ Rural Health 2010, 26(4):333-341. 
38. Zhao Z, Luman ET: Progress toward eliminating disparities in vaccination coverage among U.S. children, 2000-2008. Am J Prev Med 2010,

38(2):127-137.

39. Dunlop DD, Manheim LM, Sohn MW, Liu X, Chang RW: Incidence of functional limitation in older adults: the impact of gender, race, and chronic conditions. Arch Phys Med Rehabil 2002, 83(7):964-971.

40. Rubin GS, Bandeen-Roche K, Huang GH, Munoz B, Schein OD, Fried LP, West SK: The association of multiple visual impairments with selfreported visual disability: SEE project. Invest Ophthalmol Vis Sci 2001, 42(1):64-72.

\section{Pre-publication history}

The pre-publication history for this paper can be accessed here: http://www.biomedcentral.com/1471-2415/12/5/prepub

\section{doi:10.1186/1471-2415-12-5}

Cite this article as: Vela et al.: Eye care utilization by older adults in low, middle, and high income countries. BMC Ophthalmology 2012 12:5.

\section{Submit your next manuscript to BioMed Central} and take full advantage of:

- Convenient online submission

- Thorough peer review

- No space constraints or color figure charges

- Immediate publication on acceptance

- Inclusion in PubMed, CAS, Scopus and Google Scholar

- Research which is freely available for redistribution

Submit your manuscript at www.biomedcentral.com/submit
C Biomed Central 